\title{
Predictors of Mood Response to Acute Tryptophan Depletion: A Reanalysis
}

Linda Booij, M.Sc., Willem Van der Does, Ph.D., Chawki Benkelfat, M.D., J. Douglas Bremner, M.D., Philip J. Cowen, M.D., Maurizio Fava, M.D., Christian Gillin, M.D., Marco Leyton, Ph.D., Polly Moore, Ph.D., Katharine A. Smith, Ph.D., and Willem A. Van der Kloot, Ph.D.

Acute tryptophan depletion (ATD) induces depressive symptoms in $50-60 \%$ of selective serotonin reuptake inhibitor (SSRI) treated, recovered depressed patients. However, no reliable predictors of mood response to ATD have been established. In the present study, individual subject data of six ATD studies were pooled ('megaanalysis') in order to investigate the mediating role of clinical, demographic and biochemical characteristics in the mood response to ATD. A procedure was developed to make different versions of the Hamilton scale comparable. Recurrent depressive episodes, female gender, prior exposure to SSRI antidepressant treatment and previous serious suicidal thoughts/attempts all appear to be independent predictors of mood response to ATD. Chronicity of illness is the most powerful predictor. Residual symptoms of depression were not found to predict response to ATD. ATD may be useful to study the mechanism of action of SSRI antidepressants and individual biological vulnerability of the serotonin system. Whether the effects of ATD represent a reversal of the action of SSRI antidepressants or individual vulnerability probably depends upon the timing of the procedure in the course of remission of a depressive episode.

[Neuropsychopharmacology 27:852-861, 2002] (C) 2002 American College of Neuropsychopharmacology. Published by Elsevier Science Inc.
KEY WORDS: Tryptophan depletion; Serotonin; Amino acids; Depression; Mood; Hamilton Depression Rating Scale

Acute tryptophan depletion (ATD) is a technique used to study serotonin (5-hydroxytryptamine; 5-HT) brain

From the Department of Psychology (LB, WVdD, WAVdK) and Department of Psychiatry (WVdD) Leiden University, The Netherlands, Department of Psychiatry, McGill University, Montréal, Canada (CB, ML), Department of Psychiatry, Emory University, Atlanta (JDB), Department of Psychiatry, University of Oxford, Oxford, UK (PJC, KAS), Department of Psychiatry, Massachusetts General Hospital and Harvard Medical School, Boston, MA (MF), and Department of Psychiatry, University of California at San Diego and VA San Diego Healthcare System, San Diego, USA (CG, PM).

Address correspondence to: Dr. A.J.W. Van der Does, Department of Psychology, Leiden University, Wassenaarseweg 522333 AK Leiden, The Netherlands. Tel.: + 3171527 3377; Fax: + 3171527 4678; E-mail: vanderdoes@fsw.leidenuniv.nl

Received December 19, 2001; revised April 10, 2002; accepted April 18, 2002.

Online publication: $4 / 23 / 02$ at www.acnp.org/citations/ Npp042302289. function in mood disorders. In this paradigm, 5-HT function is temporarily lowered by deprivation of its precursor L-Tryptophan (Trp), an amino acid essential for 5-HT synthesis. It has been suggested that behavioral response to ATD might be informative about the pathophysiology of clinical depression and the mechanisms mediating antidepressant efficacy.

A number of studies have demonstrated that ATD temporarily induces depressive symptoms in remitted depressive patients treated with antidepressant medication (Delgado et al. 1990; 1999; Spillman et al. 2001). The recurrence of symptoms appears to be highest in subjects treated with a selective serotonin reuptake inhibitor (SSRI) (Delgado et al. 1990, 1994, 1999).

However, not all patients react to ATD; even in SSRItreated patients, ATD exacerbates symptoms in $50-60 \%$ of investigated patients (Van der Does 2001a). This raises the question of what factors determine response to ATD. It has been argued that induced depressive 
symptoms are limited to recently remitted, medicated patients (Moore et al. 1998). However, clinically significant symptom increases have been observed in unmedicated patients who were fully remitted for at least four months (Smith et al. 1997). It has also been suggested that depressed subjects with a history of suicidality are more vulnerable to ATD (Leyton et al. 1997), but moodlowering effects have also been shown in patients without a history of suicidal ideation (Neumeister et al. 1998). Other proposed factors are extent of depletion (Spillman et al. 2001; Van der Does 2001a,b), quality of response to medication and number of prior depressive episodes (Spillman et al. 2001). Convincing evidence has been found for none of these factors, possibly due to the lack of statistical power.

A strategy to increase statistical power is 'mega-analysis' or 'meta-analysis of original data' (Olkin 1995). In contrast to 'traditional' meta-analysis, in which the 'unit' of analyses is the study, in mega-analysis the data from each subject are retained, allowing more sophisticated analyses of the individual characteristics that might mediate the effects. The present study used mega-analysis to investigate the mediating role of clinical, demographic and biochemical characteristics in the mood response to ATD.

\section{METHODS}

\section{Participants}

The studies that were included in the reanalysis are listed in Table 1. Eight research groups that had published one or more ATD studies in remitted depressed patients were approached. One research group did not reply to three mailings. Another group accepted the invitation to participate, but failed to provide data for six months.
The total dataset consisted of 74 depressed patients in remission. Results from patients with a primary diagnosis of bipolar disorder $(n=3)$ were excluded, in order to obtain a more homogeneous sample. The demographic and clinical characteristics of the remaining 71 subjects are shown in Table 2. All patients were either free of antidepressant medication or were treated with an SSRI at the time of taking part in the experiment.

In all studies, exclusion criteria were: (1) current or past psychotic disorder; (2) a history of neurological or endocrine disease; (3) pregnancy or lactation; (4) excessive alcohol consumption; and (5) excessive dieting. Diagnoses had been made according to DSM-III-R or DSM-IV criteria, using validated structured interviews. Moore et al. (1998) included only males, whereas Smith et al. (1997) included only females. All subjects had given written informed consent.

\section{Designs and Procedures}

All studies had been conducted using a double-blind cross-over design. In each study, the L-tryptophan deficient amino acid (AA) mixture had been made according to the method used by Young et al. (1985). The amount was reduced by about $20 \%$ on the basis of the lower average weight of women in Smith et al. (1997) and in Leyton et al.(1997, 2000). Two types of control drinks were used. In Moore et al. (1998) and in Spillman et al. (2001), the control drink consisted of a $25 \%$ strength dose of the L-tryptophan deficient mixture ( 25 g AA), following the procedure of Krahn et al. (1996). In the other studies, the control drink contained the same AA as the Trp deficient mixture plus $2.3 \mathrm{~g} / 100 \mathrm{~g}$ L-tryptophan.

In each study, subjects arrived at the laboratory after fasting overnight. Subjects were instructed to consume the AA mixture within $2 \mathrm{~h}$. Mood ratings and blood

Table 1. Summary of Studies that Were Included in the Reanalysis.

\begin{tabular}{|c|c|c|c|c|}
\hline References & Site & Sample characteristics & Treatment & Results \\
\hline $\begin{array}{l}\text { Spillmann et al. } \\
\text { (2001) }\end{array}$ & Boston, MA & $\begin{array}{l}\text { Major depression in clinical } \\
\text { remission }(\mathrm{n}=10) .\end{array}$ & SSRI & $\begin{array}{l}\text { Significant increase in HRSD-6 } \\
\text { scores. } 6 / 10 \text { relapsed after ATD }\end{array}$ \\
\hline Smith et al. (1997) & Oxford, UK & $\begin{array}{l}\text { Major depressive episode, } \\
\text { fully remitted }(\mathrm{n}=15) \\
\text { Females. }\end{array}$ & $\begin{array}{l}\text { Medication free. Prior } \\
\text { treatment: SSRI, } \\
\text { TCA or } \\
\text { psychotherapy }\end{array}$ & $\begin{array}{l}\text { Significant increase in HRSD-17 } \\
\text { scores. } 5 \text { patients full relapse; } 5 \\
\text { patients partial relapse. }\end{array}$ \\
\hline Moore et al. (1998) & San Diego, CA & $\begin{array}{l}\text { Major depressive episode, } \\
\text { fully remitted }(\mathrm{n}=10) \\
\text { Males. }\end{array}$ & SSRI & $\begin{array}{l}\text { Small increase in HRSD-24 scores, } \\
\text { not clinically significant. 0/10 } \\
\text { relapsed after ATD. }\end{array}$ \\
\hline $\begin{array}{l}\text { Bremner et al. } \\
\text { (1997) }\end{array}$ & New Haven, CT & $\begin{array}{l}\text { Major depression in clinical } \\
\text { remission }(n=21)\end{array}$ & SSRI & $\begin{array}{l}\text { Small increase in HRSD-25 scores, } \\
\text { not clinically significant. } 7 / 21 \\
\text { relapsed after ATD. }\end{array}$ \\
\hline $\begin{array}{l}\text { Leyton et al. } \\
\qquad(1997 ; 2000)\end{array}$ & Montréal, Canada & $\begin{array}{l}\text { Major depressive episode, } \\
\text { fully remitted }(n=18)\end{array}$ & $\begin{array}{l}\text { Medication free. Prior } \\
\text { treatment: SSRI, } \\
\text { TCA or } \\
\text { psychotherapy }\end{array}$ & $\begin{array}{l}\text { No effect on HRSD-17 scores } \\
\text { (1997). Increase in HRSD-17 } \\
\text { scores (2000). }\end{array}$ \\
\hline
\end{tabular}


Table 2. Demographic and Clinical Characteristics of the Subjects Included in the Pooled Dataset $(n=71)$.

\begin{tabular}{lc}
\hline Variable & Mean (SD) \\
\hline Age (years) & $39.1(11.2)$ \\
Male (\%) & $\mathrm{n}=27(38 \%)$ \\
Number of prior depressive episodes & $3.3(3.5)$ (range: $1-40)$ \\
$\quad(S D)$ & \\
Duration of remission in months (SD) & $18.8(24.2)$ (range: $0-89)$ \\
SSRI treated & $\mathrm{n}=54(76 \%)$ \\
TCA & $\mathrm{n}=2(2.8 \%)$ \\
Psychotherapy & $\mathrm{n}=5(7.0 \%)$ \\
Other medications & $\mathrm{n}=1(1.4 \%)$ \\
Untreated & $\mathrm{n}=3(4.2 \%)$ \\
Unknown & $\mathrm{n}=6(8.4 \%)$ \\
Ongoing treatment (all SSRI) & $\mathrm{n}=40(56.3 \%)$ \\
Fully remitted & $\mathrm{n}=40(56.3 \%)$ \\
History of serious suicidal thoughts & $\mathrm{n}=17(24 \%)$ \\
$\quad$ or attempts & (incomplete sample) \\
\hline
\end{tabular}

samples were obtained prior to and 5-8 $\mathrm{h}$ after ingestion of the AA mixture. Medicated patients continued their medication while participating in the study, including the test days. Prior to each session, subjects were kept on a low Trp diet for 12-24 h. The procedure was repeated a couple of days later; subjects who had received the Trp deficient mixture in the first session received the control drink in the second session, and vice versa.

\section{Variables}

Only variables recorded in at least two studies were considered for inclusion in the reanalysis. All studies had used the Hamilton Rating Scale for Depression (HRSD) (Hamilton 1960) to assess mood changes, using a $6,17,24$ or 25 item version. Other included variables were: free and total plasma Trp levels (\% of reduction after ingestion of the AA mixture relative to baseline), gender, number of prior depressive episodes (based on DSM criteria), duration of remission in months, type of antidepressant treatment (SSRI vs. other), current antidepressant medication use (SSRI vs. no medication), remission status (fully vs. partially remitted) and suicidality (history of serious suicidal thoughts/attempts vs. none). Type of antidepressant treatment implies the type of treatment during the most recent episode. The definition of remission was based on DSM-criteria, as had been done in each of the original studies.

Duration of remission and number of prior depressive episodes were assessed retrospectively in all studies, mostly by means of self-reported information and medical records. This implies that these measures may not be very reliable, particularly in subjects who had a high number of previous episodes or who had been in remission for a long time. For that reason, these vari- ables were categorized. For chronicity of depression, the sample was split into groups with a single episode $(n=18)$ and recurrent episodes $(n=52)$. For duration of remission, the split was at shorter $(\mathrm{n}=46)$ or longer than 12 months remission $(n=24)$.

\section{Missing Data}

Only change scores of the HRSD and plasma Trp levels were available in the study by Bremner et al. (1997). These patients could therefore not be included in linear regression analyses. They were all taking SSRI medication at the time of the study. There were no differences in terms of gender, depressive episodes or duration of remission between this group and the patients included in the regression analysis. Five patients in the pooled dataset had no free and total Trp assessments in both conditions. For two patients, total plasma Trp levels could not be obtained in the control condition. For one of these, free plasma Trp levels were also missing. Free Trp levels were unavailable in the depletion condition for one patient. One patient had a large increase in free and total Trp levels $(217 \%$ and $20 \%$, respectively; no data in the control condition). These values were considered coding errors and were excluded in the analysis. For one patient, the mood ratings in the control condition, the number of prior depressive episodes and duration of remission were unavailable. Information about type of antidepressant treatment was missing for six patients.

\section{Data Screening}

Prior to analysis, data were screened for accuracy and completeness by reconstructing published tables from the datasets. The assumptions of linearity, normal distribution and homogenous variance were checked graphically by means of residual plots (Weisberg 1985). Outliers and influential data points were examined using Cook's distance and Mahalonobis distances.

\section{Computation of Statistically Comparable Mood Scores}

Since the HRSD versions were different in each study, these scores had to be made statistically comparable. Although a validation study demonstrated that different versions of the HRSD are strongly correlated (O'Sullivan et al. 1997), a closer look at their Table 2 (p. 382) makes clear that there is no simple formula describing this relationship. For instance, a score of 5 on the HRSD- 6 item version is not necessarily equivalent to 20 on the 24 item version. However, the relative rank of the HRSD scores will be similar for the different item versions.

A statistical method to express the relative rank is transformation of the original score into a Z-score. A 
Z-score expresses the deviation from the mean in standard deviation units, and emphasizes the relative position of the score into a distribution (Hays 1988). Hence, for each HRSD score in the dataset, a standardized HRSD score is calculated by the formula: $Z_{i t}=\left(X_{i t c j}-\right.$ $\left.\mathrm{M}_{b j}\right) / \mathrm{SD}_{b j}$, where $\mathrm{X}_{i t c j}$ is the score of subject $i$ at time point $t$ (pre vs. post intervention) in condition $c$ (ATD vs. control testing) on HRSD version $j, M_{b j}$ is the mean score at baseline $(t=0)$ on HRSD version $j$, and $\mathrm{SD}_{b j}$ is the standard deviation of HRSD version $j$ at $t=$. For instance, the mean score at baseline on the HRSD-17 is 2.10 $(S D=1.79)$. If a subject has a HRSD-17 score of 2 at baseline and 18 after ATD, the Z-scores will be -0.06 at baseline and 8.88 after ATD.

In Spillman et al. (2001), Smith et al. (1997), and Bremner et al.(1997), a clinically significant recurrence in depressive symptoms after ATD (i.e. responder to ATD: depressive 'relapse') was explicitly defined. However, the definitions differed among studies. In order to examine potential differences among criteria, each criterion was expressed as a standardized score. An additional criterion used by Delgado et al. (1990) was also standardized, based on the mean and standard deviation of the HRSD-25 scores before ATD described in their Table 1 (p. 412). The standardized criteria were applied to all subjects, implicating that five dichotomous responder definitions (Smith et al. (1997) used two definitions) were computed for each subject according to five criteria.

\section{Correlates and Predictors of Mood Effects of ATD}

To assess the predictive power of clinical and demographic factors of mood response to ATD, hierarchical multiple regression analyses were conducted. The dependent variable was the change from baseline on the ATD session (standardized post score minus standardized pre score), minus the change from baseline after control testing. Since there is convincing evidence that the effect is highest in SSRI treated patients (Delgado et al. 1990, 1999), the type of antidepressant treatment was forced into the regression equation as the first predictor. Next, the following variables were entered stepwise: gender, number of prior depressive episodes, duration of remission, current antidepressant medication use, remission status, chronicity of illness (single episode vs. recurrent episodes) and duration of remission. The relationship between mood response to ATD and suicidality was analyzed by means of General Linear Model (GLM) for repeated measures, using condition (ATD vs. control testing) and time (pre vs. post intervention) as within subjects factors and suicidality (attempts/thoughts vs. none) as between subjects factors.

In order to correct for inflated probability of a type I error and capitalizing on chance, more stringent criteria were used. The semi-partial correlation of a predictor with the dependent variable had to have a $p$-value of .01 or less to be entered into the regression equation and its contribution was removed if the $p$-value exceeded .05. Regression models were significant if the $p$-value was .05 or less. Group differences in change in free and total plasma Trp levels were examined with univariate GLM or nonparametric equivalents in case of non-normal distribution of the data.

\section{RESULTS}

\section{Biochemical Changes}

Five to seven hours after depletion, free Trp levels were reduced by $75.3 \%$ (SD: 20.5 , range: $12.5 \%-100 \%$ ) of their initial value. In the control condition, the change in free plasma Trp levels varied from an increase of $233 \%$ to a reduction of $71.0 \%$ (mean: $24.6 \%$ (increase); SD: 69.9). Total Trp was reduced by $76.7 \%$ (SD: 15.3 ; range $25.0 \%-$ $96.3 \%$ ) in the ATD condition and varied in the control condition from an increase of $137.4 \%$ to a reduction of $63.3 \%$ (mean: $10.2 \%$ (increase); SD: 44.3 ).

The percentage change of free and total Trp levels as a function of gender and condition are shown in Table 3. The reduction in free plasma Trp levels was significantly larger in females than in males after ATD $(z=$ $-3.50, d f=45, p<.001)$. The reduction in total plasma Trp levels following depletion also tended to be larger in females, but this was not significant $(z=-1.72, d f=$ $45, p=.08$ ). There were no gender differences in plasma Trp levels in the control condition. No significant correlation was found between the mood effects of ATD and $\%$ change in total $\left(r_{s}=-0.05, \mathrm{~ns}\right)$ or free plasma $\operatorname{Trp}$ levels $\left(r_{s}=0.08, \mathrm{~ns}\right)$.

\section{Relapse Rate after ATD}

Forty-six percent of the patients showed a clinically significant increase of depressive symptoms after ATD, based on the criteria of the individual studies. Smith et al. (1997) used the most stringent definition of a responder to ATD (partial relapse: $44 \%$ ). More liberal criteria were used by Spillmann et al. (2001) and Bremner et al. (1997) (both 52\%). The relapse rate according to the definitions of Delgado et al. was $46 \%$. Hence, the definitions used in the different studies are quite comparable, and lead to approximately $50 \%$ responders. A full 'relapse', as defined by Smith et al. (1997), is observed in one in five patients.

\section{Correlates and Predictors of Mood Effects of ATD}

Two subjects had a large Mahalonobis distance $(>14)$ and were considered multivariate outliers. These subjects were left out of analysis. Results of the multiple regression analyses are shown in Table 4. Type of prior 
Table 3. The Means (SD) of \% Change in Plasma Trp Measures, Broken Down by "Gender" and "Condition (ATD vs. Control Testing)". A Higher Score Corresponds With More Reduction after Ingestion of the AA Mixture.

\begin{tabular}{|c|c|c|c|c|}
\hline & \multicolumn{2}{|c|}{$\begin{array}{c}\text { ATD } \\
\text { Means (SD) }\end{array}$} & \multicolumn{2}{|c|}{$\begin{array}{l}\text { Control Testing } \\
\text { Means (SD) }\end{array}$} \\
\hline & Males & Females & Males & Females \\
\hline Free $\operatorname{Trp}$ (\% reduction) & $\begin{array}{c}64.0(20.5) \\
\text { range: } 12.5-93.4\end{array}$ & $\begin{array}{c}81.5(17.9)^{*} \\
\text { range: } 25.4-100\end{array}$ & $\begin{array}{c}-35.05(81.7) \\
\text { range: }-233.3-38.5\end{array}$ & $\begin{array}{c}-19.4(64.0) \\
\text { range: }-170.6-71.0\end{array}$ \\
\hline Total Trp (\% reduction) & $\begin{array}{c}72.4(16.6) \\
\text { range: } 40.7-92.0\end{array}$ & $\begin{array}{c}79.2(14.1) \\
\text { range: } 25-96.3\end{array}$ & $\begin{array}{c}-13.3(40.7) \\
\text { range:-113.7-39.4 }\end{array}$ & $\begin{array}{c}-8.8(46.4) \\
\text { range: }-137.4-63.3\end{array}$ \\
\hline
\end{tabular}

* Significantly different from males $(p<.001)$.

antidepressant treatment, that was entered first, accounted for $7.3 \%$ of the variance in the mood response. This was not significant. When chronicity entered in the equation, the unique contribution of type of antidepressant treatment became significant, with total explained variance $32.8 \%$. The unique contribution of gender was also significant and increased total explained variance to $44.4 \%$. Duration of remission, remission status, current antidepressant medication use, and the actual number of prior depressive episodes did not increase total explained variance to a statistically significant degree. The sign of the regression coefficients $(B)$ indicated that prior treatment with an SSRI, being female, and chronicity predict a larger mood response to ATD.

Generalizability of the three predictor model was evaluated by means of the leave-one-out procedure. $\mathrm{N}$ multiple regression models were conducted, each using $\mathrm{N}-1$ subjects. The mean multiple correlation coefficient varied from 0.63 to 0.69 (mean $0.66 ; \mathrm{R}^{2}=0.43$ ). Hence, the differences between the values obtained with $\mathrm{N}-1$ subjects and the model described in Table 4 are quite small, indicating that the model has good cross-validity power. The effects of chronicity and gender as a function of intervention (ATD vs. control testing) and time of assessment (pre vs. post intervention) are shown in Figure 1 and 2, respectively.

Since women had a larger biochemical response to ATD than men, the difference in mood response was analyzed more carefully. The stepwise regression analysis was rerun $(n=42)$, forcing type of prior antidepressant medication, gender, and chronicity, as well as reduction in free Trp levels into the equation. The unique contribution of chronicity and type of prior antidepressant medication remained significant $(p<.01)$; the contribution of gender was significant at $p=.04$, though above our adjusted level of 0.01 . The contribution of reduction in free Trp levels was not significant $(p=.71)$. The mood response did not correlate with baseline severity of depression ( $r=0.23$; ns).

Three studies contained information about the history of suicidal ideation (Smith et al. 1997; Leyton et al. 1997, 2000). These studies used the HRSD-17. Two groups were formed; a group without $(\mathrm{n}=17)$ and a group with a history of suicidal ideation (serious thoughts or one or more suicide attempts) $(\mathrm{n}=13)$. Previously suicidal patients had more depressive symptoms following ATD than subjects without a history of suicidal thoughts or attempts ( $F$ $=11.44, \mathrm{df}=1,27, p=.02$ ). Standardized HRSD scores were calculated separately for patients who had serious suicidal thoughts but had never shown suicidal behavior ('ideation' group; $\mathrm{n}=7$ ) and for patients with a history of one or more suicide attempts ('attempt' group; $\mathrm{n}=6$ ). GLM analyses showed that the attempt group had significantly more depressive symptoms following ATD than subjects without any suicidal ideation $(\mathrm{F}=9.93 ; \mathrm{df}=1,20$; $p=.005)$. The 'ideation' group had more depressive symptoms than subjects with no suicidal ideation $(\mathrm{F}=$ $5.55 ; \mathrm{df}=1,21 ; p=.03$ ). There were no significant differences between the 'attempt' group and the 'ideation' group $(\mathrm{F}=0.37$, $\mathrm{df}=1,11, p=\mathrm{ns})$. There were also no significant group differences in the control condition. Effects of condition for each subgroup are expressed in Figure 3.

\section{DISCUSSION}

The present 'mega-analysis' confirms that ATD elicits a clinically significant recurrence of depressive symp-

Table 4. Summary of the multiple regression analysis $(n=44)$.

\begin{tabular}{|c|c|c|c|c|c|c|}
\hline Step & Variable Entered & B & $\beta$ & $\mathbf{R}^{2}$ change & $F$ change & $\mathbf{R}^{2}$ \\
\hline 1 & Prior antidepressant treatment & -2.72 & -0.44 & 0.07 & 3.00 & 0.07 \\
\hline 2 & History of prior depressive episodes & 2.86 & 0.48 & 0.26 & $14.06^{* *}$ & 0.33 \\
\hline 3 & Gender & 1.98 & 0.36 & 0.12 & $7.49 *$ & 0.44 \\
\hline
\end{tabular}



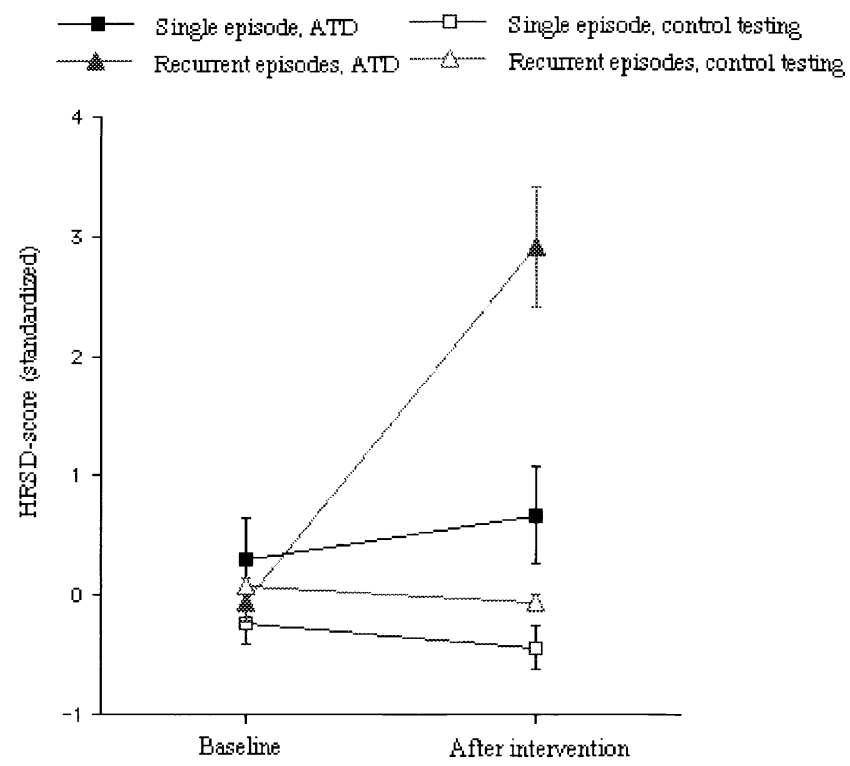

Figure 1. The means ( $\pm \mathrm{SE}$ ) of the HRSD (Z-scores), for patients with single vs. recurrent episodes. A higher score corresponds to more feelings of depression.

toms in approximately $50 \%$ of remitted depressed patients, whereas the control mixtures are inactive. A smaller proportion, about $20 \%$, fulfilled the criteria of a 'full blown relapse'. The number of subjects that fulfilled the more stringent criterion is also small in ATD studies that were not included in the reanalysis. For instance, although Delgado et al. (1990) reported a relapse in 14 of 21 subjects $(67 \%)$, converting their scores provided in Table 1 to standardized scores, shows that 3 of 21 patients had a full relapse (14\%). This suggests that, even in recently remitted patients, a clinical relapse is uncommon (Moore et al. 2000). The general image seems to be that ATD causes a complete or near return of depression. However, an intermediary term, such as 'partial relapse' or 'depressive exacerbation' may be more appropriate to describe the mood effects of ATD.

The strongest independent predictor of mood response to ATD was chronicity (single vs. recurrent episodes). This suggests that there are differences in 5-HT vulnerability between these groups of individuals. Since the number of episodes was not associated with more mood lowering effects to ATD this raises the possibility that dysregulation of the 5-HT system may occur after as few as two episodes.

The biological differences between subjects with a single episode and those with recurrent episodes require further study. No ATD study has compared the response to ATD in these two groups, but one study presented data in sufficient detail to compare findings for different types of patients. Delgado et al. (1990) reported a relapse rate of 14 out of 21 depressed patients

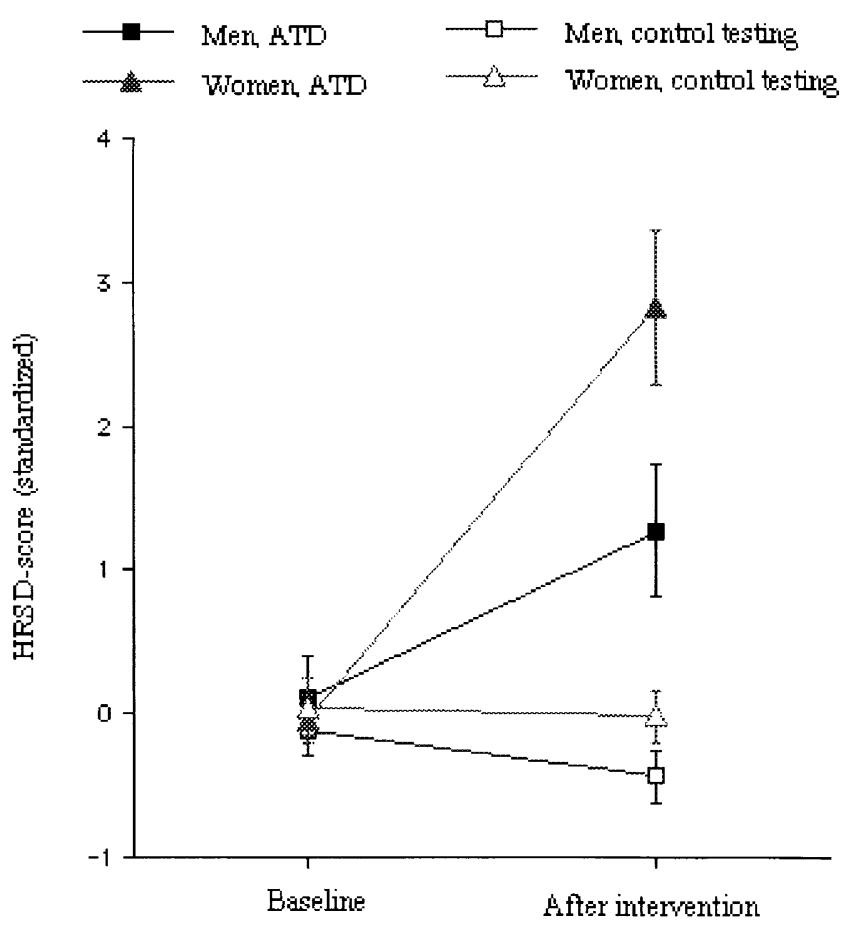

Figure 2. The means ( $\pm \mathrm{SE}$ ) of the HRSD (Z-scores) for men and women. A higher score corresponds to more feelings of depression.

in clinical remission. Visual inspection of their Table 1 (p. 412) reveals that only two of eight first-episode patients 'relapsed' after ATD (versus 12 of 13 patients with more than one episode). Consequently, six of the seven non-responders were first-episode patients.

These data are of particular interest because each new episode increases the risk of chronicity (Keller et al. 1992; Mueller et al. 1999). At present there is preliminary evidence that the mood response to ATD can predict a depressive episode one year after the challenge (Moreno et al. 2000). Future studies may further investigate the clinical significance of the mood response to ATD with respect to outcome and prediction of risk for recurrence, particularly in first-episode patients.

A significant difference in the magnitude of reduction in free Trp levels between males and females was observed in the ATD condition. Similar, though not statistically significant, gender differences have been reported in healthy individuals (Smith et al. 1997; Nishizawa et al. 1997). The lack of statistical significance may reflect the smaller sample sizes, compared with the present study.

Women also showed larger mood-lowering effects to ATD than men. This larger mood-lowering effect in women was not accounted for by the greater Trp depletion nor by the investigated clinical characteristics, including number of past episodes, duration of remission, 


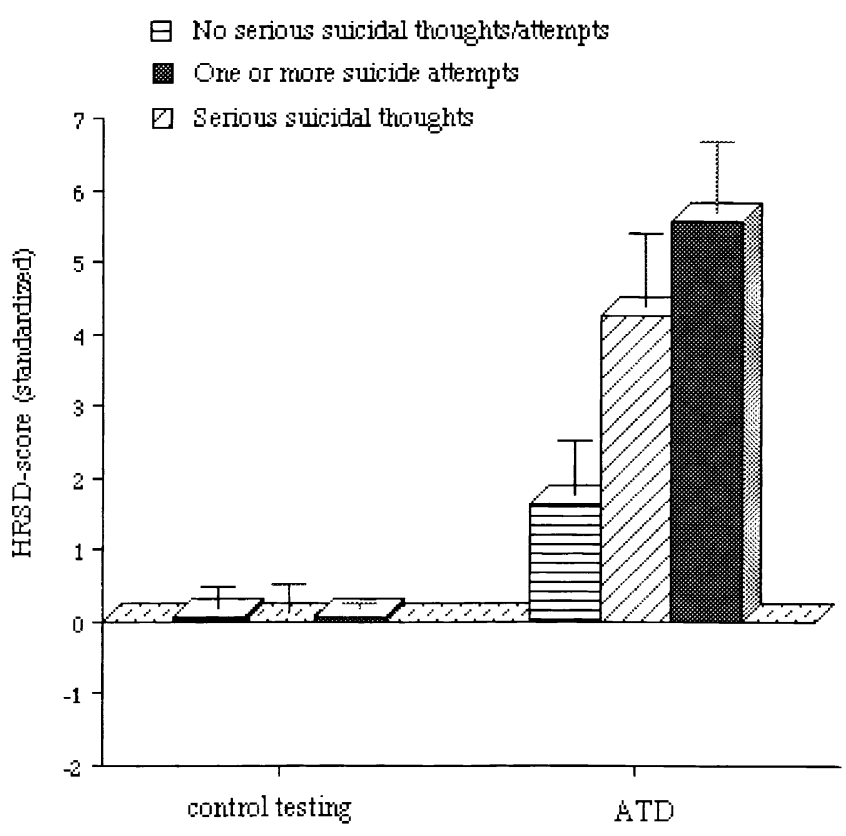

Figure 3. The means ( $\pm \mathrm{SE}$ ) of the HRSD (Z-scores) as a function of history of suicidality. Values are expressed as change from baseline. A higher score corresponds to more feelings of depression.

remission status, current SSRI treatment, past antidepressant treatment or suicidality.

The results of the present study are in accordance with findings in healthy volunteers. ATD is more likely to have mood-lowering effects (albeit small and subclinical) in healthy women than men (Ellenbogen et al. 1996; Smith et al. 1997). A PET $\alpha-\left[{ }^{11} \mathrm{C}\right]$ methyl-L-tryptophan study suggests that ATD leads to greater decreases in brain 5-HT synthesis in women than in men (Nishizawa et al. 1997). Differences between healthy men and women have also been observed in cerebrospinal fluid (CSF) concentrations of 5-hydroxyindoleacetic acid (higher in women) (Agren et al. 1986), neuroendocrine responses to 5-HT challenges (larger in women) (Goodwinn et al. 1992) and 5- $\mathrm{HT}_{2}$ receptor binding in several parts of the central nervous system (CNS) (lower in women) (Biver et al. 1996). On the basis of these studies, it can be concluded that, at least in healthy subjects, there are gender differences in 5-HT metabolism in the CNS and in the periphery. The gender difference in mood response to ATD found in the present study extends previous 5-HT challenge findings in healthy samples.

The gender differences in mood response to ATD in remitted depressed patients is also of interest in view of a recent finding that women may respond to the SSRI sertraline more often than men, whereas men may respond more favorably to the tricyclic antidepressant imipramine (Kornstein et al. 2000). Evidence exists that estrogen hormones facilitate 5-HT receptor sensitivity (Joffe and Cohen 1998). Hormonal factors may play a role in gender differences in 5-HT brain function and in risk and treatment outcome of depression.

The unique contribution of gender did not reach the significance level of $1 \%$ after the greater lowering of free Trp in women was controlled for, but the effect was not eliminated $(p=.04)$. This suggests that the greater sensitivity of recovered depressed women to ATD may reflect a greater impairment of 5-HT function. Future studies should further explore the relationship between magnitude of reduction of Trp, mood, and gender.

As expected, type of antidepressant treatment predicted response to ATD. Subjects who had received an SSRI showed larger mood responses than patients who had been treated otherwise. However, current antidepressant (SSRI) treatment was not associated with a larger mood effect. This contrasts with previous reports that patients currently being treated with SSRIs are particularly vulnerable to mood-lowering effects following ATD (Delgado et al. 1990); however, this might reflect a difference between recently remitted patients and those who have been in remission for over 18 months.

Mood-lowering effects of ATD were more pronounced in patients with a history of suicidal thoughts or attempts. The data suggest that the 5-HT system may be more disturbed in depressed individuals with suicidal tendencies than in those without (Leyton et al. 1997, 2000).

The influence of suicidality on mood response to ATD may reflect differences in impulse control or high inward-aggression levels. This notion is supported by the behavioral effects of ATD found in subjects who have an increased risk for developing disorders that are characterized by impulsive behaviors, including aggression (Cleare et al. 1995; Pihl et al. 1995), substance abuse (LeMarquand et al. 1995) and bulimia nervosa (Weltzin et al. 1995; Smith et al. 1999).

Some evidence suggests that abnormalities of the 5-HT system may be limited to a subtype of depression; i.e. those in which anxiety and aggression dysregulation are the primary dysfunctions (Van Praag 1991, 1996). A subgroup of depressed patients with instability of aggression regulation may be particularly prone to the mood-lowering effects of ATD. It is noteworthy that all data of the subjects that had a history of serious suicidal thoughts or attempts in the patients were from fully remitted patients. This indicates that the possible underlying disturbed aggression regulation related to abnormalities in 5-HT brain function may be a trait characteristic, rather than an expression of symptoms (Van Praag 1991).

Some limitations deserve attention. First, the variable 'history of suicidal ideation' was assessed retrospectively and based on self-reported information. This implies that classification may be difficult. On the other 
hand, the distinction between "one or more attempts" and "no history of suicidal ideation" is probably reliable. Information about suicidality was only available for a subset of the dataset, precluding it from being entered into the regression equation. However, the absence of an association between suicidality and the other patient characteristics examined suggests that suicidality is an independent predictor. No ATD experiments were found that focused explicitly on the relationship between suicidality and the mood response to ATD. The present results suggest that future studies should gather more detailed information about the history of suicidal tendencies (Leyton et al. 1997).

\section{Tryptophan Depletion as a Model of SSRI Antidepressant Mechanisms vs. Individual Biological Vulnerability}

The present study did not support a number of previously suggested associations. Duration of remission was not associated with the mood response to ATD. Also, differences between partial and fully remitted patients were far from significant. It should be noted however that the latter variable, as well as the variable 'current antidepressant medication use' were nested within individual studies, making these variables less appropriate for the present reanalysis. An alternative explanation for the finding that current use of antidepressants does not predict response to ATD may be a methodological one; this variable probably correlates highly with prior use of SSRIs (which is a significant predictor) and with chronicity (as patients with recurrent episodes are typically kept on antidepressants), and may not present enough spread (as many investigators tended to recruit patients on SSRIs for this challenge) to detect the effect of current treatment.

One major difference with Delgado et al. $(1990,1999)$ is that 69 of the 71 patients included in this reanalysis had shown improvement for at least one month (mean: 18.3 months). In contrast, subjects enrolled in the Delgado studies were clinically stable for only two to four weeks and were on antidepressant medication not longer than 10 weeks. Possibly, if applied soon after the onset of treatment response, ATD interferes with the action of SSRIs (Moore et al. 1998). The present study suggests that this dependency may be restricted to only the first few weeks after starting antidepressant treatment. Once the therapeutic effect has been reached, a moodlowering response to ATD may reflect individual biological vulnerability of the 5-HT system, rather than mechanism of antidepressant action.

\section{Methodological Considerations}

A methodological point of concern is the method of pooling data of individual studies itself. It has been suggested that pooling individual subject data provides the most valid and reliable way of addressing research questions that cannot be adequately resolved by individual studies (Stewart et al. 1993). It has the advantage of a more detailed data-analysis and increased statistical power. In contrast to traditional meta-analysis, individual subject characteristics are retained, allowing a more sensitive analysis. Despite these advantages, a limitation is that the reliability and validity of the present study is dependent on the reliability and validity of the individual studies (Wolf 1986). Combining information from different studies assumes that the studies are uniform enough to pool them. To investigate this potential bias, a leave-one-out procedure was conducted, which showed that the predictors have good cross-validity power. Moreover, all predictors were patient characteristics that varied within studies, rather than nested characteristics of the individual studies. Also, all diagnoses and assessments were conducted according to standardized, reliable methods. Therefore, it is unlikely that the effect of the three-predictor model is mediated by a confounding variable such as study site.

Some further issues deserve attention. First, we could not include the data from all investigators who have published ATD studies. Second, we could not include all 71 available subjects in the regression analysis. On the other hand, 15 subjects per predictor is usually sufficient for a reliable regression equation, one that will cross-validate well (Stevens 1996). Third, several other clinical variables that could not be included may mediate the mood response to ATD, e.g. duration of treatment, time-off medications and other types of previous treatment, (e.g., tricyclic antidepressants [TCAs], monoamine oxidase inhibitors [MAOIs], electroconvulsive therapy [ECT], and psychotherapy).

An additional issue concerns the different HRSD versions. The present study has illustrated a way to make different item versions comparable if only total scores rather than individual item scores are available. Previous research has shown that the 6,17, and 24-item versions are highly positively correlated before and after pharmacological treatment, indicating that different item versions are of comparable sensitivity to detect changes in depressive symptomatology over time (O'Sullivan et al. 1997). The notion of a positive correlation between the different HRSD versions may appear self-evident, but it is important, since it implies that the relative rank of the scores is similar across different scale versions. This property justified the standardization procedure that made these versions directly comparable. Considering the widespread use of the HRSD and the many different versions that exist, the standardization procedure described here may be useful to other researchers wishing to combine results from different studies.

In conclusion, this reanalysis shows that recurrent depressive episodes, female gender, treatment with an 
SSRI and history of suicidal thoughts/attempts are predictive of a mood-lowering response to ATD. Together, the results suggest that mood-lowering responses to ATD might be informative for two purposes: (1) identifying serotonergic mechanisms of antidepressant efficacy; and (2) identifying 5-HT related differences in biological vulnerability to depression.

\section{ACKNOWLEDGMENTS}

The preparation of this paper has been facilitated by NWOMW grant 903-57-132 to Dr. Van der Does.

\section{REFERENCES}

Agren H, Mefford IN, Rudorfer MV, Linnoila M, Potter WZ (1986): Interacting neurotransmitter systems: a nonexperimental approach to the 5-HIAA-HVA correlation in human CSF. Psychiatry Res 20:175-193

Biver F, Lotstra F, Monclus M, Wikler D, Damhout P, Mendlewicz J (1996): Sex difference in 5HT2 receptor in the living human brain. Neurosci Lett 204:25-28

Bremner JD, Innis RB, Salomon RM, Staib LH, Ng CK, Miller HL, Bronen RA, Krystal JH, Duncan J, Rich D, Price LH, Malison R, Dey H, Soufer R, Charney DS (1997): Positron emission tomography measurement of cerebral metabolic correlates of tryptophan depletion-induced depressive relapse. Arch Gen Psychiatry 54:364-374

Cleare AJ, Bond AJ (1995): The effect of tryptophan depletion and enhancement on subjective and behavioral aggression in normal male subjects. Psychopharmacology (Berl) 118:72-81

Delgado PL, Charney DS, Price LH, Aghajanian GK, Landis H, Henninger GR (1990): Serotonin function and the mechanism of antidepressant action. Reversal of antidepressant-induced remission by rapid depletion of plasma tryptophan. Arch Gen Psychiatry 47:411-418

Delgado PL, Price LH, Miller HL, Salomon RM, Licinio J, Krystal JH, Heninger GR, Charney DS (1991): Rapid serotonin depletion as a provocative challenge test for patients with major depression: relevance to antidepressant action and the neurobiology of depression. Psychopharm Bull 27:321-330

Delgado PL, Miller HL, Salomon RM, Licinio J, Krystal JH, Moreno FA, Heninger GR, Charney DS (1999): Tryptophan-depletion challenge in depressed patients treated with desipramine or fluoxetine: Implications for the role of serotonin in the mechanism of antidepressant action. Biol Psychiatry 46:212-220

Ellenbogen MA, Young SN, Dean P, Palmour RM, Benkelfat C (1996): Mood response to acute tryptophan depletion in healthy volunteers: sex differences and temporal stability. Neuropsychopharmacology 15:465-474

Goodwin GM, Murray CL, Bancroft J (1994): Oral d-fenfluramine and neuroendocrine challenge: problems with the $30 \mathrm{mg}$ dose in men. J Affec Disord 30:117-122

Hamilton M (1960): A rating scale for depression. Neurol Neurosurg Psychiatry 23:56-62
Hays WL (1988): Statistics, 4th ed. New York, Holt, Rinehart, Winston

Joffe H, Cohen LS (1998): Estrogen, serotonin and mood disturbance. Where is the therapeutic bridge? Biol Psychiatry 44:798-811

Keller MB, Lavori PW, Mueller TI, Endicott J, Coryell W, Hirschfield RM, Shes T (1992): Time to recovery, chronicity, and levels of psychopathology in major depression, a 5-year prospective follow-up of 431 subjects. Arch Gen Psychiatry 49:809-816

Kornstein SG, Schatzberg AF, Thase ME, Yonkers KA, McCullough JP, Keitner GI, Gelenberg AJ, Davis SM, Harrison WM, Keller MB (2000): Gender differences in treatment response to sertraline versus imipramine in chronic depression. Am J Psychiatry 157:1445-1452

Krahn LE, Lu PY, Klee G, Delgado PR, Lin SC, Zimmerman RC (1996): Examining serotonin function: a modified technique for rapid tryptophan depletion. Neuropsychopharmacology 15:325-328

LeMarquand DG, Benkelfat C, Pihl RO, Palmour RM, Young SN (1999): Behavioral disinhibition induced by tryptophan depletion in nonalcoholic young men with multigenerational family histories of paternal alcoholism. Am J Psychiatry 156:1771-1779

Leyton M, Young SN, Benkelfat C (1997): Relapse of depression after rapid depletion of tryptophan [letter]. Lancet 349:1840-1841

Leyton M, Young SN, Blier P, Ellenbogen MA, Palmour RM, Ghadirian A, Benkelfat C (1997): The effect of tryptophan depletion on mood in medication-free, former patients with major affective disorder. Neuropsychopharmacology 16:294-297

Leyton M, Ghadirian AM, Young SN, Palmour RM, Blier P, Helmers KF, Benkelfat C (2000): Depressive relapse following acute tryptophan depletion in patients with major depressive disorder. J Psychopharmacol 14:294-297

Moeller FG, Dougherty DM, Swann AC, Collins D, Davis CM, Cherek DR (1996): Tryptophan depletion and aggressive responding in healthy males. Psychopharmacology (Berl) 126:97-103

Moore P, Gillin JC, Bhatti T, DeModena A, Seifritz E, Clark C, Stahl S, Rapaport M, Kelsoe J (1998): Rapid tryptophan depletion, sleep, electroencephalogram, and mood in men with remitted depression on serotonin reuptake inhibitors. Arch Gen Psychiatry 55:534-539

Moore P, Landolt H, Seifritz E, Clark C, Bhatti T, Kelsoe J, Rapaport M, Gillin JC (2000): Clinical and physiological consequences of rapid tryptophan depletion. Neuropsychopharmacology 23:601-622

Moreno FA, Heninger GR, McGahuey CA, Delgado PL (2000): Tryptophan depletion and risk of depression relapse: a prospective study of tryptophan depletion as a potential predictor of depressive episodes. Biol Psychiatry 48:327-329

Mueller TI, Leon AC, Keller MB, Solomon DA, Endicott JE, Coryell W, Warshaw M, Maser JD (1999): Recurrence after recovery from major depressive disorder during 15 years of observational follow-up. Am J Psychiatry 156:1000-1006

Murphy DL, Mueller EW, Hill JL, Tolliver TJ, Jacobsen FM (1989): Comparative anxiogenic, neuroendocrine, and 
other physiologic effects of m-chlorophenylpiperazine given intravenously or orally to healthy volunteers. Psychopharmacology (Berl) 98:275-282

Neumeister A, Turner EH, Matthews JR, Postolache TT, Barnett RL, Rauh M, Vetticad R, Kasper S, Rosenthal NE (1998): Effects of tryptophan depletion vs. catecholamine depletion in patients with seasonal affective disorder in remission with light therapy. Arch Gen Psychiatry 44:524-530

Nishizawa S, Benkelfat C, Young SN, Leyton M, Mzengeza S, De Montigny C, Blier P, Diksic M (1997): Differences between males and females in rates of serotonin synthesis in human brain. Proc Natl Acad Sci USA 94:5308-5313

Olkin I (1995): Meta-analysis reconciling the results of independent studies. Statist Med 14:457-472

O'Sullivan RL, Fava M, Agustin C, Baer L, Rosenbaum JF (1997): Sensitivity of the six-item Hamilton Depression Rating Scale. Acta Psychiatr Scand 95:379-384

Pihl RO, Young SN, Harden P, Plotnick S, Chamberlain B, Ervin FR (1995): Acute effect of altered tryptophan levels and alcohol on aggression in normal human males. Psychopharmacology (Berl) 119:353-360

Smith KA, Fairburn CG, Cowen PJ (1997): Relapse of depression after rapid depletion of tryptophan. Lancet 349:915-919

Smith KA, Clifford EM, Hockney RA, Clark DM, Cowen PJ (1997): Effect of tryptophan depletion on mood in male and female volunteers: a pilot study. Hum Neuropsychopharmacol 12:111-117

Smith KA, Fairburn CG, Cowen PJ (1999): Symptomatic relapse in bulimia nervosa following acute tryptophan depletion. Arch Gen Psychiatry 56:171-176

Spillmann MK, Van der Does AJW, Rankin MA, Vuolo RD,
Alpert JE, Nierenberg AA, Rosenbaum JF, Hayden D, Schoenfeld D, Fava M (2001): Tryptophan depletion in SSRI-recovered depressed outpatients. Psychopharmacology (Berl) 155:123-127

Stevens J (1996): Applied multivariate statistics for the social sciences, 3rd ed. Hillsdale, NJ, Lawrence Erlbaum

Stewart LA, Parmar MK (1993): Meta-analysis of the literature or of individual data: is there a difference? Lancet 341:418-421

Van der Does AJW (2001a): The effects of tryptophan depletion on mood and psychiatric symptoms: review. J Affec Disord 64:107-119

Van der Does AJW (2001b): The mood-lowering effect of tryptophan depletion: possible explanation for discrepant findings. [letter]. Arch Gen Psychiatry 58:200-201

Van Praag HM (1991): Serotonergic dysfunction and aggression control. Psychol Med 21:15-19

Van Praag HM (1996): Faulty cortisol/serotonin interplay. Psychopathological and biological characterisation of a new, hypothetical depression subtype (SeCa depression). Psychiatry Res 65:153-157

Weisberg S (1985): Applied Linear Regression. New York, Wiley

Weltzin TE, Fernstrom MH, Fernstrom JD, Neuberger SK, Kaye WH (1995): Acute tryptophan depletion and increased food intake and irritability in bulimia nervosa. Am J Psychiatry 152:1668-1671

Wolf FM (1986) Meta-analysis. Quantitative methods for research synthesis. Beverly Hills, CA, Sage University

Young SN, Smith SE, Pihl RO, Ervin FR (1985): Tryptophan depletion causes a rapid lowering of mood in normal males. Psychopharmacology (Berl) 87:173-177 